\title{
Buenas prácticas laborales, ¿nuevas prácticas familiares?
}

\author{
Good work practices, new family practices? \\ Roberto Celedón
}

\section{Introducción ${ }^{1}$}

En el marco del debate por la conciliación entre trabajo y familia (Astelarra, 2005; Connel, 1997), la Presidenta Michelle Bachelet, en junio del 2006, dictó el Código de Buenas Prácticas Laborales Sobre No Discriminación (CBPL). Este código es obligatorio para el sector público y voluntario para las empresas privadas. Tiene como objetivo favorecer y promover la compatibilidad entre las obligaciones laborales y las responsabilidades familiares. Los responsables de su implementación son la Unidad de Personas o Recursos Humanos de los Servicios, pero a su vez se encuentran implicados otros actores en la formulación de las medidas.

Es por ello que se requiere conocer el ciclo de producción de los indicadores que permitieron a los tomadores de decisión implementar la medida. Este proceso implica no sólo un análisis económico, o de costo-beneficio, sino que además de organización del trabajo e indicadores sociales. Este último se encuentra expuesto a juicio de valor y a formas de conceptualizar los datos que define una determinada opción o dirección (Parsons, 2007). Se hace necesario conocer la implementación de este Código desde los diversos actores implicados en la toma de decisiones.

En este artículo se presenta el resultado del análisis de la Flexibilidad Horaria, definida como una Buena Práctica Laboral (BPL), asociado al objetivo de la conciliación entre las obligaciones laborales y responsabilidades familiares, y su incidencia en el ejercicio de la corresponsabilización de los varones en las tareas relativas al cuidado y al trabajo doméstico. Específicamente se analizó su implementación en el Ministerio de Vivienda y Urbanismo (MINVU).

\footnotetext{
${ }^{1}$ Este trabajo se enmarca dentro del proyecto FONDECYT Nํㅗ 1110553, "Hombres en Chile. Conciliación, Corresponsabilidad y Uso del tiempo: tensiones y conflictos entre familia y trabajo" y corresponde a parte de la investigación desarrollada en el Estudio de Caso "Código De Buenas Prácticas Laborales: Incorporación de los hombres en la conciliación trabajo ? familia" para el Magíster en Gestión y Políticas Públicas.

*Dirección de correspondencia [Correspondence address]: Roberto Celedón,

E-mail: rob.celedon@gmail.com
}

\section{Metodología}

Este es un estudio de carácter exploratoriodescriptivo, sustentado sobre un enfoque metodológico cualitativo. Se pretende explorar la incidencia que ha tenido la implementación del Código de Buenas Prácticas Laborales, y específicamente el objetivo de conciliación de responsabilidades laborales y obligaciones familiares en los sentidos y vivencias de los varones hacia una mayor corresponsabilización en las tareas relativas al cuidado familiar. Para ello, se optó por la Buena Práctica de "Flexibilidad Horaria", por considerarse que es una práctica que permanece en el tiempo, que cuenta con un pronunciamiento de la Contraloría General de la República, y que informantes claves de la Dirección Nacional del Servicio Civil (DNSC) lo describen como una práctica que ha ido permeando y generalizando en la administración del Estado.

Se recoge información de los distintos actores implicados en el diseño e implementación de la BPL (encargados de personal, bienestar, dirigentes de la asociación de funcionarios, directivos de recursos humanos). Para contrastar la información de éstos actores, se entrevistó a funcionarios varones que al menos estuvieran trabajando unos años previos a la implementación de la medida. Las entrevistas se analizaron desde la técnica del análisis de contenido de los relatos de los /as entrevistados/as en torno a las variables relevantes, de manera de contribuir a comprender los sentidos y vivencias de los funcionarios, e identificar elementos facilitadores/obstaculizadores y sus implicancias para el ejercicio de la corresponsabilización del varón en las tareas familiares. Asimismo se buscó recoger insumos desde los actores claves que facilitasen la elaboración de recomendaciones de política pública en la materia.

\section{Resultados}

\section{CBPL y Flexibilidad Horaria}

\section{Nivel de conocimiento}

Destaca entre los funcionarios varones entrevistados el desconocimiento de la asociación entre la flexibilidad horaria y la Conciliación Trabajo-Familia. 
Hay un reconocimiento a la búsqueda de menor rigidez, de un estándar más humano del sistema, y que a ellos les fue de utilidad para evitar atrasos y descuentos. Esto contrasta con los esfuerzos desde Recursos Humanos por difundir la medida entre los funcionarios, pero es coherente con parte de las motivaciones en torno a la implementación de la medida, que era realizar un mejor control de asistencia y disminuir la recarga administrativa asociada al nivel de atrasos.

Este desconocimiento de la flexibilidad horaria también se ve refrendado en relación al CBPL. Se desconoce que está asociado a un instructivo presidencial, ni que busca establecer principios de mayor equidad e igualdad entre los funcionarios públicos. Si bien se reconoce el año de inicio de la implementación del CBPL, y el haber sido premiado por el Servicio Civil, algunos lo asocian a nivel intuitivo a buenos hábitos o buen hacer.

A diferencia de los funcionarios varones, a nivel de los directivos existe una clara asociación entre la Flexibilidad Horaria y el objetivo de Conciliación trabajo ? familia.

Se establecen pocos matices cuando se observa que las prácticas conciliatorias se asocian principalmente para la mujer. Destaca la política de Flexibilidad Horaria como una medida universal, pero a nivel simbólico se percibe como una práctica que va a permitir a la mujer conciliar mejor el ámbito público y privado. Dicho de otra manera, se podría pensar que a nivel simbólico no es una práctica dirigida hacia los varones, y si bien ellos se benefician de ésta, no lo internalizan en la dirección que el objetivo pretende.

\section{Cambio en las rutinas laborales de entrada y salida}

Los cambios de hábitos de los funcionarios ?que era una de las mayores aprehensiones durante la toma de decisiones- según todas las autoridades directivas entrevistadas no fue tal. Los hábitos de entrada y salida se mantuvieron relativamente parejos, incluso, según estudios internos realizados a los cuatro meses posteriores, el promedio de entrada al trabajo disminuyó entre 8 y 10 minutos en promedio. Sin embargo, esta no fue la realidad de los funcionarios varones entrevistados, quienes en promedio atrasaron entre 10 y 15 minutos su hora de entrada.

Existe consenso para señalar que la flexibilidad horaria es una práctica que se utiliza en determinadas circunstancias excepcionales, tanto para llegar o para salir más temprano por un compromiso pos- terior.

Una de las entrevistadas manifiesta un matiz, haciendo una distinción por género. El que las mujeres entran más temprano y se retiran a la hora, no así los hombres quienes tienden a quedarse hasta más tarde, a pesar de que entraron temprano a trabajar. Se lo explica porque son las mujeres quienes siguen haciéndose cargo de los aspectos asociados a los hijos/as.

\section{Ante emergencias o imprevistos}

Los funcionarios varones relatan que ante situaciones de emergencia, dependiendo de la jefatura directa, es posible organizarse para retirarse o no ir a trabajar. Sin embargo, esta es una práctica que sigue principalmente depositada en la mujer. A su vez, se reconoce que sus compañeras de trabajo son las que más solicitan ese tipo de permisos.

\section{Valoración}

Los funcionarios varones expresan una alta valoración de la flexibilidad horaria. Valoran, en primer lugar, que ya no llegan tarde y que ya no se les descuenta por atraso, que pueden ir a dejar tranquilos a sus hijos/as al colegio, y que ante una emergencia en la mañana logran organizarse para llegar al trabajo.

El valor llega con la comparación con su experiencia anterior, pero también cuando la flexibilidad es o no compartida con sus parejas. Ellos relatan que el tipo de trabajo, y el horario de entrada de sus parejas, también determinan su relación con el horario de entrada. La medida no es sólo valorada por lo que ha significado en el ámbito familiar, sino que también por lo que ha implicado en las relaciones laborales o directamente en el clima de trabajo. Esta es una constatación desde los directivos implicados en la implementación de esta Buena Práctica.

Considerando que esta medida podría haber ocasionado situaciones de tensión por abusos de parte de algunos funcionarios, los entrevistados fueron categóricos en señalar que la práctica de llegar siempre atrasado es de casos aislados. Además, según estadísticas de la encargada de personal, disminuyeron significativamente los atrasos.

\section{Conciliación}

Los entrevistados destacan que las relaciones hombre ? mujer ha cambiado, que el rol de proveer es una tarea compartida, y que participan de 
las responsabilidades parentales, teniendo tareas específicas a cargo, como ir a dejar a los hijos/as al colegio o ayudarlos en las tareas escolares. Sin embargo, son menos consistentes en lo que se refiere a las tareas domésticas, lo que por un lado puede deberse a que cuentan con trabajadoras de casa particular, pero a nivel de responsabilidades y preocupaciones por estos temas existen diferencias a nivel de sus prácticas y discursos. Esta información es coherente con todos los estudios de uso del tiempo, que muestra el escaso avance en materias de responsabilidades domésticas, y un avance mayor en las tareas vinculadas a los hijos/as.

Esta forma de relacionarse con el mundo privado viene de antes de implementarse la flexibilidad horaria, y no relatan mayores cambios en sus tareas domésticas y de cuidado con la implementación de ésta medida. Los cambios en relación a las rutinas de entrada y salida del trabajo está más vinculado a la presencia o no presencia de un hijo/a.

Cabe preguntarse si la falta de influencia de las condiciones laborales para transformar prácticas de los varones, puede ser explicado en mayor medida por la visión de los directivos públicos. Considerando que las principales transformaciones se dan con la incorporación de la mujer al mundo laboral, siendo ella quien va definiendo el territorio, y el hombre cumpliendo un rol menos activo en estas transformaciones. Presentado de otro modo, el hombre en su proceso de ir cumpliendo ritos que lo demuestren como tal, en la vida adulta y con familia, se constituye como tal en la medida que trabaja y es proveedor, por tanto las exigencias familiares de conciliación se sitúan principalmente en la mujer.

Lo anterior, puede explicar, en parte, que cuando se pregunta a los funcionarios varones, por lo que saben o entienden de conciliación trabajo ? familia y qué medidas implementadas reconocen asociadas a ésta, destaca la falta de conocimiento de ellos y la asociación con tener vida familiar.

\section{Corresponsabilidad}

Existe un paulatino avance en la participación masculina en los distintos ámbitos de la vida familiar, pero también en el espacio público como son el traslado de los hijos/as al bus o jardín infantil, participación en las reuniones de colegios, y traer a los hijos/as al espacio de trabajo. Sin embargo, esta participación no es visualizada como equitativa.

Hay algunos elementos que emergen en los entrevistados que se podría situar en el eje del nivel de iniciativa en la búsqueda de mayor correspon- sabilidad, pero más bien el nivel de involucramiento depende de la pareja. La presión explícita de la pareja, inclina la balanza por privilegiar la mayor presencia del hombre en el espacio familiar.

Además de los factores culturales y generacionales que se perciben como elementos significativos hacia una mayor participación (principalmente en relación a su propia generación) de los varones en actividades vinculadas a sus hijos/as, y un relativo menor avance en lo doméstico, interesa saber cómo vinculan la implementación de la flexibilidad horaria como un factor coadyuvante de una mayor corresponsabilidad. Salvo una entrevistada, en su gran mayoría coinciden en señalar que es un aspecto poco observado, señalan que no existen diagnósticos o mediciones con respecto al tema y que más bien es una continuidad de niveles de responsabilidades previa al inicio de ésta medida.

\section{Discusión}

Los diferentes actores coinciden en señalar que la presencia de varias condiciones simultáneas permitió implementar tempranamente la flexibilidad horaria. Sin embargo, cuando se estableció dicha medida, se la vinculó a experiencias de las mujeres del Servicio,invisibilizando a los hombres como un actor en la Conciliación. Dicho de otro modo, los funcionarios hombres gozan de los privilegios o de las prerrogativas de la flexibilidad horaria, pero no participan del sentido de esta medida, que es favorecer la capacidad de conciliar entre las responsabilidades familiares y las laborales. Existen un conjunto de prácticas laborales que refuerzan más bien los roles tradicionales asignados al género.

La flexibilidad horaria es una medida altamente valorada por los distintos actores, por su incidencia positiva en el clima laboral, ya que no sólo disminuyó considerablemente los atrasos, con toda su carga simbólica, y administrativa asociada, sino que fue vista como un logro desde todos los sectores. Desde ese lugar, se entiende la consideración de la flexibilidad horaria como una BUENA PRACTICA (con mayúscula), pero no es una práctica género transformativa, sino más bien género sensible (Barker et al., 2007).

Al no asumir una perspectiva género sensible o transformativa, se termina perpetuando los mandatos culturales asociados a que es la mujer quien debe conciliar las responsabilidades del trabajo y las domésticas. Como señalan algunos/as entrevistados/as, esto implica partir por la igualdad salarial ante el mismo cargo y responsabilidades, hasta la organización del tiempo en el trabajo. Esto permite 
afirmar que la política de la flexibilidad horaria se puede circunscribir dentro de las políticas dirigidas a las necesidades de desregulación del mercado de trabajo y no necesariamente a la necesidad de conciliar, y menos aún a la corresponsabilización por parte de los varones.

Los funcionarios varones vivencian la conciliación desde un lugar más bien secundario o de colaboración. Son sus parejas las que utilizan sus días administrativos u horas extras. Esto en parte sustentado en una cultura que sostiene los estereotipos asociados al género, pero también en un campo desigual de decisión. Es posible para el hombre en la negociación elegir lo que se hace, en cambio la mujer debe asumir desde un lugar asignado. Siendo lo económico una de las dimensiones más significativas de poder en las relaciones familiares, la presencia de un cierta equivalencia en los aportes económicos de ambos a la economía familiar, no necesariamente implica una mayor equidad en lo que se refiere a los roles en la tareas domésticas y el cuidado de los hijos/as.

Asimismo, se hace necesario tener en cuenta los factores culturales asociados a las realidades generacionales y las estructuras familiares. El situar la conciliación en múltiples configuraciones familiares, intereses personales, y generacionales implica revisar prácticas y sistemas de privilegios al interior de los equipos de trabajo, así como es la realidad del cuidado de los/as funcionarios/as.

\section{Conclusiones}

Las medidas implementadas en el marco de la conciliación trabajo-familia han afectado positivamente en el clima laboral y una mejor gestión en los tiempos de llegada al trabajo, sin embargo en sí mismas presentan un escaso avance en materia de corresponsabilidad de los padres-varones. Es desde ese marco que la gestión e implementación de medidas referentes a objetivos que busque mayor equidad entre diferentes grupos, debe contemplar a los diversos actores implicados.

Un aspecto, y que introduce no solo equidad de género en las condiciones de desarrollo de las personas, sino que además equidad según las necesidades de otorgar cuidado, es lo referente a la organización del trabajo. Las organizaciones han de asegurarse de que sus formas de organizar el trabajo y sus normas impulsen valores organizacionales que incentive el principio de igualdad de para hombres y mujeres.

Si se pretende llegar a un nivel más avanzado como el reparto de tareas más equitativo y/o corresponsable, es necesario diseñar una estrategia de educación y formación en la organización, que muestre el compromiso real desde lo público hacia cómo concilian los trabajadores de la organización con el desarrollo de la vida familiar.

Esto implica que al esfuerzo de transversalizar el enfoque de género, hay que agregarle indicadores de género, que den cuenta de los niveles de corresponsabilidad. Este esfuerzo a nivel de construcción de estos indicadores, permitiría visibilizar estadísticamente la forma de organización familiar y los niveles de bienestar entre sus funcionarios.

\section{Referencias}

Astelarra, J. (2005). Políticas conciliatorias: conceptualización y tendencias. En Mora, X., editor, Cohesión Social, Políticas Públicas Conciliatorias y Presupuesto Público. Una Mirada Desde el Género, pp. 27-38. Fondo de Población de las Naciones Unidas, México D.F.

Barker, G., Ricardo, C., y M., N. (2007). Cómo hacer participar a los hombres y los niños en la lucha contra la inequidad de género en el ámbito de la salud.

Connel, R. (1997). La organización social de la masculinidad. En Valdés, T., editor, Masculinidad/es: Poder y Crisis, pp. 31-48. ISIS Internacional / FLACSO-Chile, Santiago de Chile.

Parsons, W. (2007). Políticas Públicas. Una introducción a la teoría y la práctica del análisis de las políticas públicas. Miño y Davila-FLACSO México, Buenos Aires. 